\title{
A proposal for an individualized pharmacogenetic- guided isoniazid dosage regimen for patients with tuberculosis
}

This article was published in the following Dove Press journal:

Drug Design, Development and Therapy

30 September 2015

Number of times this article has been viewed

\author{
Jin Ah Jung' \\ Tae-Eun Kim² \\ Hyun Lee ${ }^{3}$ \\ Byeong-Ho Jeong ${ }^{3}$ \\ Hye Yun Park ${ }^{3}$ \\ Kyeongman Jeon ${ }^{3}$ \\ $\mathrm{O}$ Jung Kwon ${ }^{3}$ \\ Jae-Wook Ko ${ }^{4}$ \\ Rihwa Choi ${ }^{5}$ \\ Hye-In Woo ${ }^{6}$ \\ Won-Jung Koh ${ }^{3}$ \\ Soo-Youn Lee Le $^{4}$
}

'Department of Clinical Pharmacology, Inje University College of Medicine, Inje University Busan Paik Hospital, Busan, Korea; ${ }^{2}$ Department of Clinical Pharmacology, Konkuk University Medical Center, ${ }^{3}$ Division of Pulmonary and Critical Care Medicine, Department of Medicine, ${ }^{4}$ Department of Clinical Pharmacology and Therapeutics, ${ }^{5}$ Department of Laboratory Medicine and Genetics, Samsung Medical Center, Sungkyunkwan University School of Medicine, Seoul, Korea; ${ }^{6}$ Department of Laboratory Medicine, Samsung Changwon Hospital, Sungkyunkwan University School of Medicine, Changwon, Korea

Correspondence: Won-Jung Koh Division of Pulmonary and Critical Care Medicine, Department of Medicine, Samsung Medical Center, Sungkyunkwan University School of Medicine, 8I IIwon-ro, Gangnam-gu, Seoul, Korea

Email wjkoh@skku.edu

Soo-Youn Lee

Departments of Laboratory Medicine and Genetics, Samsung Medical Center, Sungkyunkwan University School of Medicine, 8I Ilwon-ro, Gangnam-gu, Seoul, Korea

Email suddenbz@skku.edu
Background/aim: Isoniazid (INH) is an essential component of first-line anti-tuberculosis (TB) treatment. However, treatment with INH is complicated by polymorphisms in the expression of the enzyme system primarily responsible for its elimination, N-acetyltransferase 2 (NAT2), and its associated hepatotoxicity. The objective of this study was to develop an individualized INH dosing regimen using a pharmacogenetic-driven model and to apply this regimen in a pilot study.

Methods: A total of 206 patients with TB who received anti-TB treatment were included in this prospective study. The 2-hour post-dose concentrations of INH were obtained, and their NAT2 genotype was determined using polymerase chain reaction and sequencing. A multivariate regression analysis that included the variables of age, sex, body weight, and NAT2 genotype was performed to determine the best model for estimating the INH dose that achieves a concentration of 3.0-6.0 mg/L. This dosing algorithm was then used for newly enrolled 53 patients.

Results: Serum concentrations of INH were significantly lower in the rapid-acetylators than in the slow-acetylators $(2.55 \mathrm{mg} / \mathrm{L}$ vs $6.78 \mathrm{mg} / \mathrm{L}$, median, $P<0.001)$. A multivariate stepwise linear regression analysis revealed that NAT2 and body weight independently affected INH concentrations: INH concentration $(\mathrm{mg} / \mathrm{L})=13.821-0.1 \times($ body weight, $\mathrm{kg})-2.273 \times$ (number of high activity alleles of $N A T 2 ; 0,1,2)$. In 53 newly enrolled patients, the frequency at which they were within the therapeutic range of $3.0-6.0 \mathrm{mg} / \mathrm{L}$ was higher in the model-based treatment group compared to the standard treatment group (80.8\% vs $59.3 \%)$.

Conclusion: The use of individualized pharmacogenetic-guided INH dosage regimens that incorporate NAT2 genotype and body weight may help to ensure achievement of therapeutic concentrations of INH in the TB patients.

Keywords: tuberculosis, pharmacogenomics, NAT2 genotype, INH regimen

\section{Introduction}

Tuberculosis (TB) is a major public health problem worldwide, with an estimated 9.0 million incident cases and 1.5 million deaths in $2013 .^{1}$

Standard treatment for TB is a 6-month regimen that includes 2 months of isoniazid (INH), rifampin, ethambutol, and pyrazinamide, followed by 4 months of INH and rifampin with or without ethambutol. ${ }^{2,3}$ Despite the rather successful therapeutic effects of this regimen, there are still treatment failures and unmanageable adverse events that lead to discontinuation of therapy. The major adverse event induced by this multidrug regimen is liver injury. The incidence of anti-TB drug-induced hepatotoxicity ranges from $1 \%$ to $36 \%$, and mortality is not rare. ${ }^{4}$ Among these medications, INH is the major contributor to drug-induced hepatotoxicity. INH is primarily metabolized by arylamine $\mathrm{N}$-acetyltransferase 2 (NAT2), which has three phenotypes, including 
rapid-, intermediate-, and slow-acetylators. It is well known that INH-induced hepatotoxicity develops more frequently in NAT2 slow-acetylators. ${ }^{46}$ In contrast, treatment failure is likely to occur in rapid-acetylators. ${ }^{7,8}$ These findings imply that the standard regimen may not be appropriate for some patients with certain NAT2 genotypes due to failure to maintain therapeutic concentrations of INH.

Based on the hypothesis mentioned earlier, the authors proposed that determination of INH dosing according to NAT2 genotype may help to maintain patients within the therapeutic range, thereby minimizing treatment failures and adverse events. Up to now, only a few individualized INH dosing based on the genotype was applied and was not thoroughly validated in the clinical setting. In this study, we prospectively investigated factors that influence INH concentration and developed an INH concentration model to determine appropriate dosing.

\section{Materials and methods Study participants}

This study was conducted in the outpatient setting at Samsung Medical Center, Seoul, Korea. Eligible participants were patients newly diagnosed with active TB, who underwent standard four-drug treatment for 6 months: INH $(5 \mathrm{mg} / \mathrm{kg}$, usually $300 \mathrm{mg}$ ), rifampin (450 mg for $<50 \mathrm{~kg}$ or $600 \mathrm{mg}$ for $\geq 50 \mathrm{~kg}$ body weight), ethambutol (15 $\mathrm{mg} / \mathrm{kg})$, and pyrazinamide (20-30 mg/kg), given daily for 2 months and followed by INH and rifampin with or without ethambutol for 4 months. ${ }^{3}$ Those patients with abnormal hepatic function on laboratory testing (increased serum aspartate aminotransferase, alanine aminotransferase, or total bilirubin) before anti-TB treatment and underlying liver disease or systemic illness such as congestive heart failure, acute life-threatening disease, or alcoholism or disease that was resistant to INH at the start of treatment were excluded. The protocol was approved by the Institutional Review Board of Samsung Medical Center, Seoul, Korea. This study was conducted according to the principles of the Declaration of Helsinki and in compliance with applicable regulatory guidelines. All patients provided written informed consent before participating in the study.

\section{Study procedure}

All patients were treated according to the international standard treatment recommended for adults with TB. The 2-hour post-dose whole blood samples were drawn for analysis of INH concentration 1 and 4 weeks after the start of anti-TB treatment. Using these samples, NAT2 genotyping was also determined.
In order to genotype $N A T 2$, genomic DNA was extracted from peripheral blood leukocytes using the Wizard Genomic DNA Purification Kit according to the manufacturer's instructions (Promega Corporation, Fitchburg, WI, USA). Polymerase chain reaction with direct sequencing was performed with an ABI Prism 3100 genetic analyzer (Thermo Fisher Scientific, Waltham, MA, USA) using primer sets that were designed by the authors. ${ }^{9}$ The presence of any two slow alleles defined a slow-acetylator, whereas intermediate- and rapid-acetylators had one and two wild-type $N A T 2 * 4$ alleles, respectively.

Anti-TB drug-induced hepatotoxicity was designated as increase in serum alanine aminotransferase level more than twice the upper limit of the normal after anti-TB treatment, according to the criteria of drug-induced liver injuries developed by the international consensus meeting. ${ }^{10,11}$ When anti-TB drug-induced hepatotoxicity was identified, serum alanine aminotransferase, aspartate aminotransferase, and bilirubin levels were monitored every week thereafter.

\section{Determination of INH concentration}

Plasma INH concentrations were measured by highperformance liquid chromatography - tandem mass spectrometry. Analyses were performed on an Xevo TQ-S tandem mass spectrometer equipped with an ultra performance liquid chromatography (Waters, USA). The column used was a BEH Amide $(2.1 \times 150 \mathrm{~mm}, 1.7 \mu \mathrm{m})$. The mobile phases A and $\mathrm{B}$ were water with $0.1 \%$ formic acid and acetonitrile with $0.1 \%$ formic acid, respectively. After simple protein precipitation with $1 \%$ sulfosalicylic acid, the plasma samples were mixed with an internal standard (INH-D4) and centrifuged for 4 minutes. Quantitative analysis was performed in multiple reaction-monitoring mode $(\mathrm{m} / \mathrm{z} 138.0 \rightarrow 121.0$ for MPA; $142.0 \rightarrow 125.0$ ) with a total running time of 5 minutes for each sample. The linear assay range was $0.5-50 \mathrm{ng} / \mathrm{mL}$ $\left(r^{2}>0.99\right)$. Intra- and inter-day coefficients of variation were lower than $10 \%$.

\section{Statistical analysis}

Descriptive statistics are expressed as means \pm standard deviations or frequencies (\%), as appropriate. Statistical calculations were made using the Statistical Package for the Social Sciences (SPSS) version 18 for Microsoft Windows (SPSS Inc., Chicago, IL, USA). Univariate regression analysis was performed to identify potential factors associated with INH concentration. To control for potential confounders, a multivariate regression model with forward selection was used $(P=0.005)$. All statistical 
Table I Baseline characteristics of study patients $(n=153)$

\begin{tabular}{|c|c|c|c|c|}
\hline & $\begin{array}{l}\text { Rapid-acetylators } \\
(n=6 I)\end{array}$ & $\begin{array}{l}\text { Intermediate- } \\
\text { acetylators }(n=68)\end{array}$ & $\begin{array}{l}\text { Slow-acetylators } \\
(\mathrm{n}=24)\end{array}$ & $P$-value \\
\hline Sex, male (n) & $40,65.6 \%$ & $39,57.4 \%$ & $16,66.7 \%$ & 0.555 \\
\hline Age, years & $46.8 \pm 15.9$ & $50.3 \pm 16.6$ & $45.7 \pm 18.0$ & 0.351 \\
\hline Body weight, kg & $60.3 \pm 9.9$ & $58.0 \pm 9.8$ & $58.3 \pm 9.1$ & 0.382 \\
\hline Aspartate aminotransferase, IU/L & $18.9 \pm 5.5$ & $21.6 \pm 7.7$ & $20.9 \pm 6.6$ & 0.079 \\
\hline Alanine aminotransferase, IU/L & $15.6 \pm 7.5$ & $19.2 \pm 12.3$ & $18.2 \pm 11.0$ & 0.160 \\
\hline Alkaline phosphatase, IU/L & $71.2 \pm 19.7$ & $74.4 \pm 22.1$ & $68.5 \pm 22.3$ & 0.478 \\
\hline
\end{tabular}

tests were two tailed, and the significance level was set at a $P$-value of 0.05 .

\section{Results}

\section{Participant demographics}

General characteristics of the 153 patients used in the development of our dosing model are described in Table 1. A total of 61 patients were genotyped as rapid-acetylators (39.9\%), 68 as intermediate-acetylators $(44.4 \%)$, and 24 as slowacetylators (15.7\%). There were no statistical differences in age, sex, body weight, body mass index, and liver function before anti-TB treatment.

\section{Relationship with INH concentration}

INH concentrations in 73 patients $(47.7 \%)$ fell outside of the defined therapeutic range of $3.0-6.0 \mathrm{mg} / \mathrm{L} ;{ }^{12} 34$ patients (22.2\%) had low INH concentrations and 39 patients $(25.5 \%)$ had high INH concentrations. To assess the factors that influenced INH concentration, a multivariate stepwise linear regression analysis was conducted with respect to age, sex, body weight, and NAT2 genotype. This analysis revealed that body weight and NAT2 genotype were independent significant factors affecting INH concentration (Table 2), while other variables did not alter INH concentration $(P>0.05)$. We found that the INH concentration decreases, on average, by $1.0 \mathrm{mg} / \mathrm{L}$ for every $10 \mathrm{~kg}$ increase in body weight (Figure 1). The INH concentrations were significantly lower in rapid-acetylators with a median of $2.55 \mathrm{mg} / \mathrm{L}$ compared to intermediate-acetylators with a mean of $4.43 \mathrm{mg} / \mathrm{L}$ and slow-acetylators with a mean of $2.55 \mathrm{mg} / \mathrm{L}$ (Figure 1). According to the regression analysis, the equation that best predicts INH concentration is as follows:

INH concentration $(\mathrm{mg} / \mathrm{L})=13.821-0.1 \times($ body weight, $\mathrm{kg})$ $-2.273 \times$ (number of high activity alleles of $N A T 2$ genotype; $0,1,2$ )

To achieve an INH concentration of $3.0-6.0 \mathrm{mg} / \mathrm{L},{ }^{12}$ doses of Table 3 were calculated based on the above equation. For example, $70 \mathrm{~kg}$ patients who had slow-, intermediate-, and rapid-acetylators required INH doses of 200, 300, and $400 \mathrm{mg}$, respectively.

\section{Model application}

This dosing model was applied in 53 newly enrolled patients (30 males and 23 females). The mean age, body weight, aspartate aminotransferase, and alanine aminotransferase before anti-TB treatment were $45.8 \pm 15.4$ years, $61.0 \pm 10.7 \mathrm{~kg}, 24.4 \pm 16.4 \mathrm{IU} / \mathrm{L}$, and 20.1 $\pm 18.7 \mathrm{IU} / \mathrm{L}$, respectively. Patients were randomly assigned to a standard treatment group, INH dose of 300 or $200 \mathrm{mg}$ based on the body weight, $\mathrm{n}=25$, or model-based treatment group, INH dose determined based on the developed model, $\mathrm{n}=28$. The distribution of the NAT2 genotype was not different between groups ( $P=0.490)$. INH was dosed at 100, 200, 300 , or $400 \mathrm{mg}$ depending on body weight and NAT2 genotype of the patient in the model-based treatment group (Table 3). Doses of other anti-TB drugs were not different between the standard treatment group and model-based treatment group.

Table 2 Multivariate regression analyses of study variables and their effects on isoniazid concentration in patients with active tuberculosis

\begin{tabular}{lllll}
\hline & Coefficient $(\boldsymbol{\beta})$ & Standard error & P-value & $\begin{array}{l}\text { 95\% confidence } \\
\text { interval }\end{array}$ \\
\hline Number of NAT2*4 allele $=0$ & 4.245 & 0.670 & $<0.001$ & $2.920,5.570$ \\
Number of NAT2*4 allele $=1$ & 2.037 & 0.491 & $<0.001$ & $1.067,3.007$ \\
Body weight, kg & -0.064 & 0.028 & 0.021 & $-0.119,-0.010$ \\
\hline
\end{tabular}

Abbreviation: NAT2, N-acetyltransferase 2 . 

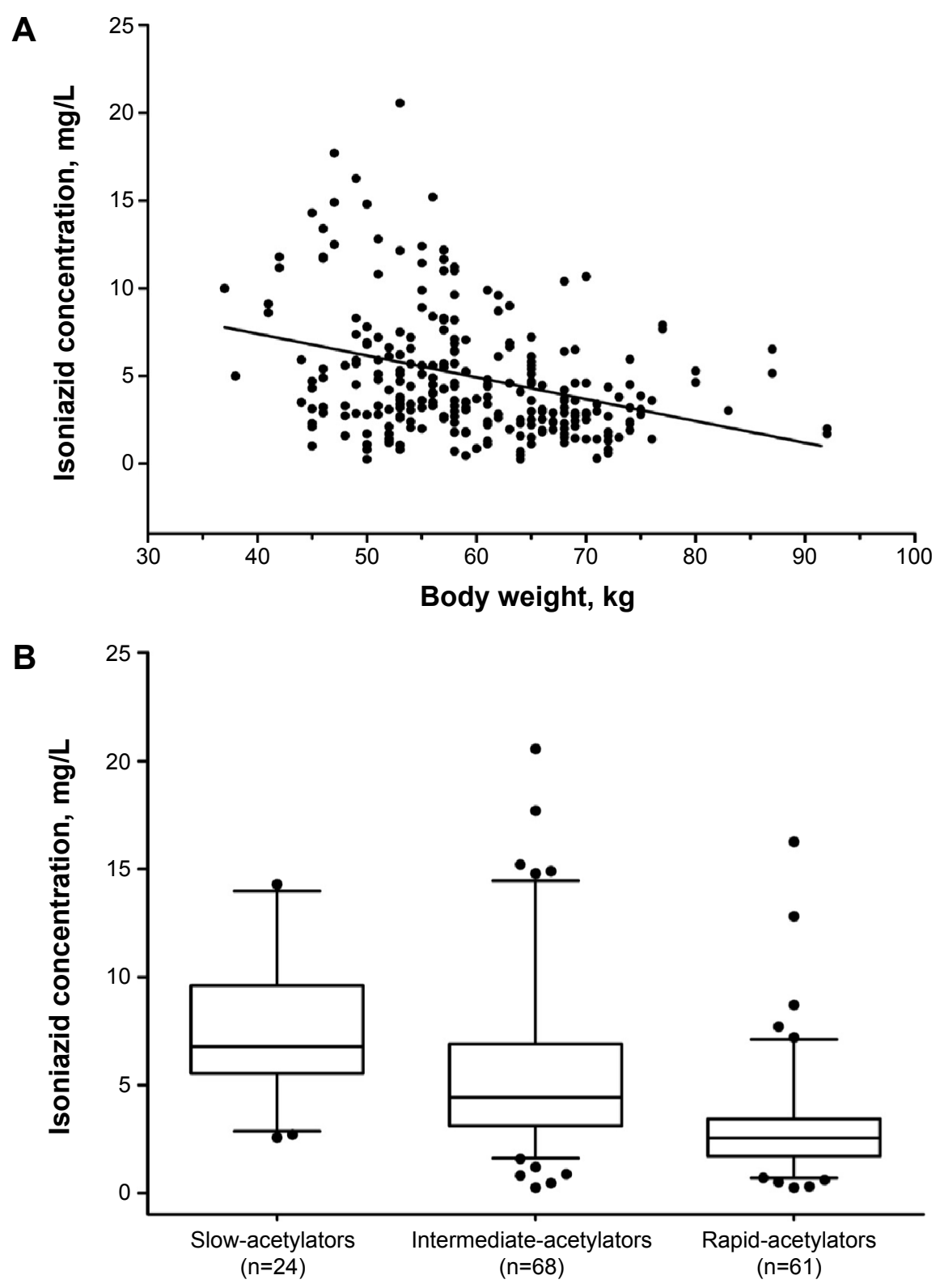

Figure I Individual concentrations of isoniazid relative to body weight (A) and NAT2 genotype (B).

The frequencies at which the standard treatment group and model-based treatment group were within the therapeutic range of $3.0-6.0 \mathrm{mg} / \mathrm{L}$ were $40.0 \%$ and $71.4 \%$ in the subjects who required dose change based on the model, respectively (Figure 2).

Table 3 Calculated daily dose of isoniazid in relative to NAT2 genotype and body weight using the developed model

\begin{tabular}{llllll}
\hline NAT2 status & \multicolumn{5}{l}{ Body weight, $\mathbf{~ g}$} \\
\cline { 2 - 6 } & $\mathbf{4 0}$ & $\mathbf{5 0}$ & $\mathbf{6 0}$ & $\mathbf{7 0}$ & $\mathbf{8 0}$ \\
\hline Slow-acetylators & $100 \mathrm{mg}$ & $200 \mathrm{mg}$ & $200 \mathrm{mg}$ & $200 \mathrm{mg}$ & $300 \mathrm{mg}$ \\
Intermediate-acetylators & $200 \mathrm{mg}$ & $200 \mathrm{mg}$ & $300 \mathrm{mg}$ & $300 \mathrm{mg}$ & $300 \mathrm{mg}$ \\
Rapid-acetylators & $300 \mathrm{mg}$ & $300 \mathrm{mg}$ & $300 \mathrm{mg}$ & $400 \mathrm{mg}$ & $400 \mathrm{mg}$ \\
\hline
\end{tabular}

Abbreviation: NAT2, N-acetyltransferase 2.

\section{Anti-TB drug-induced hepatotoxicity}

A total of six of 153 patients (3.9\%) experienced druginduced hepatotoxicity, two subjects with rapid-acetylators (3.3\%) and four subjects with intermediate- or slowacetylators $(4.3 \%)$. In newly enrolled 53 patients, only one subject $(1.9 \%)$ with intermediate acetylation activity $(N A T 2 * 4 / * 7 \mathrm{~B})$ exhibited experienced drug-induced hepatotoxicity.

\section{Discussion}

In TB populations with high rates of treatment failure and acquired resistance, most patients have low drug concentrations. ${ }^{13}$ The slow-acetylator genotype is an independent 


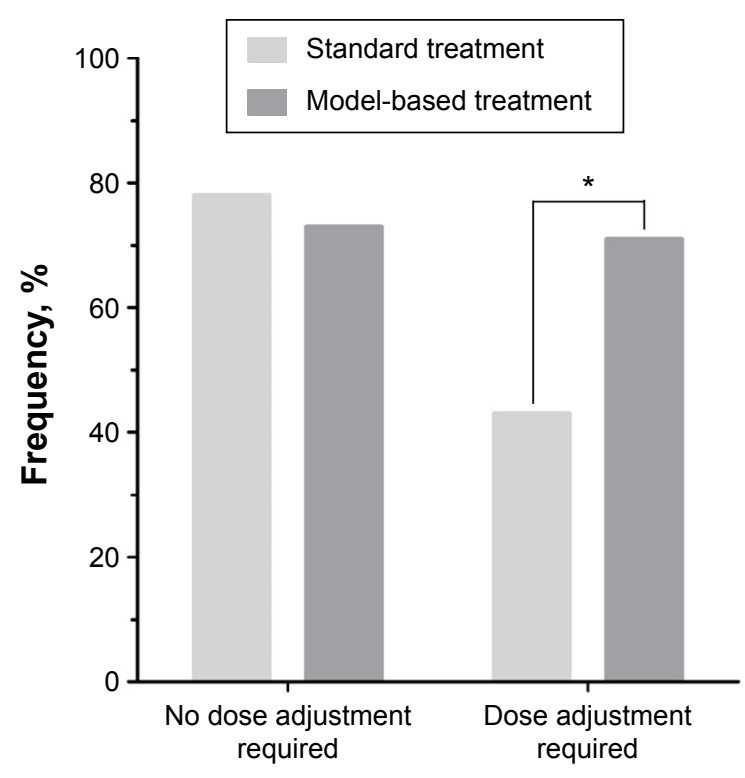

Figure 2 Frequency that patients were within the therapeutic range of $3.0-6.0 \mathrm{mg} / \mathrm{L}$ while using standard treatment and model-based treatment.

Notes: Frequency within the therapeutic range of $3.0-6.0 \mathrm{mg} / \mathrm{L}$ was significantly lower in the group requiring dose changes in the standard treatment group compared to the model-based treatment group $(P=0.013)$. $* P<0.05$.

risk factor for INH-induced hepatotoxicity when INH is used in combination with rifampicin. On the other hand, the rapid-acetylator genotype may result in therapeutic failure due to low plasma concentrations. Hence, we sought to identify significant factors that affect INH concentration and develop a new dosing regimen to better maintain INH concentrations within the desired therapeutic range. In our study, the prevalence of low concentrations of INH was $22.2 \%$, which was similar to that of previous reports in Koreans and Africans. ${ }^{12,14}$ As expected, the prevalence of low INH concentrations was high in rapid-acetylators (64.7\%) and that of high INH concentrations was high in slow-acetylators $(69.6 \%)$. Body weight and NAT2 genotype were factors that affected INH concentration in this study. As patients had higher body weight and a greater number of high-activity alleles with respect to NAT2 genotype, their INH concentrations were low. Corresponding results have been reported in several studies. ${ }^{14,15} \mathrm{In}$ a study by Zabost et al, the average concentration of INH was twofold to sevenfold higher among slow-acetylators compared to rapid- and intermediate-acetylators. ${ }^{15}$ Likewise, serum concentrations of INH were positively associated with the dose/kg ratio of concentration to body weight of acetyl-INH to INH in Korean populations. ${ }^{14}$ A population pharmacokinetic study in a large sampling of healthy Caucasians showed that the NAT2 genotype alone accounted for $88 \%$ of variability in apparent INH clearance. ${ }^{16}$ In this population, body weight had no effect, which is thought to be attributed to the otherwise homogenous characteristics of healthy subjects.

The developed model was successfully applied to newly diagnosed pulmonary TB patients in a pilot study. Low and high INH concentrations were infrequent in the patients who received the model-based regimen. Similarly, INH-related liver injury and early treatment failure were significantly lower in the NAT2-genotype-guided treatment groups (approximately 7.5, 5, and $2.5 \mathrm{mg} / \mathrm{kg}$ of INH for rapid-, intermediate-, and slow-acetylators, respectively) compared to a conventional standard treatment in Japanese patients. ${ }^{17}$ This result supports the hypothesis that appropriate dose adjustment of INH at the beginning of therapy is important for avoiding drug-related liver injury and treatment failure. Therapeutic monitoring of INH using a 2-hour post-dose sampling with or without a 6-hour postdose sampling can be considered. ${ }^{18-20}$ However, collecting blood samples at specific times is not feasible in the clinical setting for logistical and financial reasons. NAT2 genotyping can be performed using blood previously obtained during the routine safety check, and thus, a genotypebased regimen does not require additional blood samples. The frequency of rapid-acetylator genotypes in the Asian population is much higher than that in Caucasians..$^{21,22}$ Considering this interethnic difference in NAT2 genotype frequencies, our model-based regimen may only effectively improve early treatment success rates in Asians. ${ }^{17}$

Results of our pilot study need to be reevaluated and confirmed in a large-scale population study that examines definitive clinical outcomes, such as rates of treatment failure, sputum culture conversion rates, and adverse events, including INH-induced hepatotoxicity.

An individualized pharmacogenetic-guided INH dosing regimen that takes into consideration NAT2 genotype and body weight was developed using data from this prospective trial to better ensure therapeutic concentrations of INH. Additionally, our pilot study applied this new INH dosing regimen and demonstrated potential for a subsequent largescale study.

\section{Acknowledgment}

This study was supported by a grant of the Korean Health Technology R\&D Project, Ministry for Health and Welfare, Republic of Korea (HI13C0871).

\section{Disclosure}

The authors report no conflicts of interest in this work. 


\section{References}

1. World Health Organization Global Health Observatory. Tuberculosis. Available from: http://www.who.int/gho/tb/en/index.html. Accessed February 21, 2015.

2. World Health Organization. Guidelines for Treatment of Tuberculosis. Available from: http://www.who.int/tb/publications/2010/ 9789241547833/en/. Accessed February 23, 2015.

3. Joint Committee for the Development of Korean Guidelines for TB and Korea Centers for Disease Control and Prevention. Korean Guidelines for Tuberculosis. 2014.

4. Du H, Chen X, Fang Y, et al. Slow N-acetyltransferase 2 genotype contributes to anti-tuberculosis drug-induced hepatotoxicity: a metaanalysis. Mol Biol Rep. 2013;40(5):3591-3596.

5. Wang JY, Liu CH, Hu FC, et al. Risk factors of hepatitis during antituberculous treatment and implications of hepatitis virus load. J Infect. 2011;62(6):448-455.

6. Bose PD, Sarma MP, Medhi S, Das BC, Husain SA, Kar P. Role of polymorphic $\mathrm{N}$-acetyl transferase 2 and cytochrome $\mathrm{P} 4502 \mathrm{E} 1$ gene in antituberculosis treatment-induced hepatitis. $J$ Gastroenterol Hepatol. 2011;26(2):312-318.

7. Parkin DP, Vandenplas S, Botha FJ, et al. Trimodality of isoniazid elimination: phenotype and genotype in patients with tuberculosis. $\mathrm{Am}$ J Respir Crit Care Med. 1997;155(5):1717-1722.

8. Donald PR, Sirgel FA, Venter A, et al. The influence of human $\mathrm{N}$-acetyltransferase genotype on the early bactericidal activity of isoniazid. Clin Infect Dis. 2004;39(10):1425-1430.

9. Lee SY, Lee KA, Ki CS, et al. Complete sequencing of a genetic polymorphism in NAT2 in the Korean population. Clin Chem. 2002; 48(5):775-777.

10. Benichou C. Criteria of drug-induced liver disorders. Report of an international consensus meeting. J Hepatol. 1990;11(2):272-276.

11. Danan G, Benichou C. Causality assessment of adverse reactions to drugs - I. A novel method based on the conclusions of international consensus meetings: application to drug-induced liver injuries. $J$ Clin Epidemiol. 1993;46(11):1323-1330.

12. Kayhan S, Akgüneş A. Therapeutic monitoring of isoniazid, rifampicin, ethambutol and pyrazinamide serum levels in the treatment of active pulmonary tuberculosis and determinants of their serum concentrations. Afr J Pharm Pharmacol. 2011;5(17):2015-2041.
13. Van Tongeren L, Nolan S, Cook VJ, FitzGerald JM, Johnston JC. Therapeutic drug monitoring in the treatment of tuberculosis: a retrospective analysis. Int J Tuberc Lung Dis. 2013;17(2):221-224.

14. Um SW, Lee SW, Kwon SY, et al. Low serum concentrations of antituberculosis drugs and determinants of their serum levels. Int J Tuberc Lung Dis. 2007;11(9):972-978.

15. Zabost A, Brzezińska S, Kozińska M, et al. Correlation of $\mathrm{N}$-acetyltransferase 2 genotype with isoniazid acetylation in polish tuberculosis patients. Biomed Res Int. 2013;2013:853602.

16. Kinzig-Schippers M, Tomalik-Scharte D, Jetter A, et al. Should we use $\mathrm{N}$-acetyltransferase type 2 genotyping to personalize isoniazid doses? Antimicrob Agents Chemother. 2005;49(5):1733-1738.

17. Azuma J, Ohno M, Kubota R, et al; Pharmacogenetics-based tuberculosis therapy research group. NAT2 genotype guided regimen reduces isoniazid-induced liver injury and early treatment failure in the 6-month four-drug standard treatment of tuberculosis: a randomized controlled trial for pharmacogenetics-based therapy. Eur J Clin Pharmacol. 2013; 69(5):1091-1101.

18. Peloquin CA. Therapeutic drug monitoring in the treatment of tuberculosis. Drugs. 2002;62(15):2169-2183.

19. Alsultan A, Peloquin CA. Therapeutic drug monitoring in the treatment of tuberculosis: an update. Drugs. 2014;74(8):839-854.

20. Babalik A, Babalik A, Mannix S, Francis D, Menzies D. Therapeutic drug monitoring in the treatment of active tuberculosis. Can Respir J. 2011;18(4):225-229.

21. Cascorbi I, Drakoulis N, Brockmoller J, Maurer A, Sperling K, Roots I. Arylamine N-acetyltransferase (NAT2) mutations and their allelic linkage in unrelated Caucasian individuals: correlation with phenotypic activity. Am J Hum Genet. 1995;57(3):581-592.

22. Sunahara S, Uranom, Ogawam. Genetical and geographic studies on isoniazid inactivation. Science. 1961;134(3489):1530-1531.
Drug Design, Development and Therapy

\section{Publish your work in this journal}

Drug Design, Development and Therapy is an international, peerreviewed open-access journal that spans the spectrum of drug design and development through to clinical applications. Clinical outcomes, patient safety, and programs for the development and effective, safe, and sustained use of medicines are a feature of the journal, which

\section{Dovepress}

has also been accepted for indexing on PubMed Central. The manuscript management system is completely online and includes a very quick and fair peer-review system, which is all easy to use. Visit $\mathrm{http}: / /$ www.dovepress.com/testimonials.php to read real quotes from published authors. 